\title{
Cultural Diversity Really is Like Biological Diversity: Reply to comments on the Nature of Religious Diversity: A Cultural Ecosystem Approach.
}

\author{
David Sloan Wilson, Yasha Hartbeg, Ian F. MacDonald, Jonathan A. Lanman and \\ Harvey Whitehouse
}

We are grateful to the commentators for their stimulating reflections on our target article. Most but not all are supportive of the cultural ecosystem approach and many of the supportive comments go beyond our own contribution in developing the approach. A number of major themes emerged in the commentaries that we will attempt to address by organizing our reply into the following categories: 1 ) Biological units and units of selection; 2) Field sites for the study of cultural evolution; 3) Forming testable hypotheses; 4) More on tightness and looseness; and 5) Cultural Diversity vs. Religious Diversity.

Biological units and units of selection: The biological sciences abound with units: organs, organisms, single-species groups, multi-species ecosystems, and higherlevel taxonomic units such as genera, families, and phyla. Some of these units are discrete and easy to identify (e.g, an organism or a termite colony), others have fuzzy boundaries (e.g., most ecosystems), some are notoriously hard to define (e.g., species), and some are more salient to the biologist than to the interacting organisms (e.g., higher-level taxonomic categories). This might seem dauntingly complex (Zeitlyn, Tucker), but biologists manage to turn all of these units into productive research programs. The cultural ecosystem approach strives to do the same for the study of cultural diversity, without requiring point-for-point correspondences. Cultural inheritance mechanisms do not require "memes" that correspond to genes, for example (Henrich, Boyd and Richerson 2008).

For both biological and cultural ecosystems, it is crucial to identify the units of functional organization, which arise by a process of selection at the unit level (as discussed in section 1 of the target article). This could even be said to be the anchor concept that makes the two approaches similar. In biological ecosystems, these are most often individual organisms (not species, as emphasized by Zeitlyn and as we also emphasize in section 3 of the target article). A single-species social group and even a multispecies ecosystem can be a unit of functional organization, but only if it has been a unit of selection. Eusocial insect societies are famous examples. If you were to study single honeybees as if they were similar to solitary insect species, you would be making a profound error, equivalent to the error of assuming that an organ such as the heart is an autonomous organism.

In human cultural ecosystems, the units of functional organization can be individuals or groups, but they are groups more often than in biological ecosystems because group selection is a more potent force in cultural evolution than in genetic evolution (Richerson and Boyd 2006; Wilson 2013). This is a major development in evolutionary thought that challenges previous dogma in both evolutionary biology 
and anthropology. In the former case, individual-level selection was thought to almost always prevail over group-level selection. In the latter case, individuals were axiomatically made the unit of analysis by a philosophical stance called methodological individualism, which Paul defines as the assumption that " 'societies' and 'cultures' do not really exist as entities in themselves, but are abstractions based on the summed behavior of the similarly enculturated individuals that constitute them."

Palmer's commentary is in the tradition of methodological individualism. For him, individuals must be the unit of analysis and groups are "illusory conceptual abstractions". He regards qualifiers such as "for the most part" and "in many cases" as weaknesses in our conceptual framework, as if a more individualistic account would not need such qualifiers. We disagree. Methodological individualism must account for the same complexities of cultural diversity, in all their fuzziness, as a multi-level selection account.

We are very pleased to have Paul's commentary to juxtapose with Palmer's. Paul is one of the first socio-cultural anthropologists to take dual-inheritance theory seriously and his recent book, Mixed Messages, is filled with examples of human groups that function as corporate units, thanks to cultural mechanisms that hold disruptive within-group competition in check (Paul 2015). Viewing such cultures through the lens of methodological individualism is almost as misleading as studying honeybees as if they are solitary insects.

Deciding what is not functionally organized goes hand in hand with deciding what is functionally organized. Some early schools of thought in ecosystem ecology axiomatically assumed that whole ecosystems are functionally organized (e.g., Margelef 1963), much as the tradition of functionalism in anthropology axiomatically assumed that human cultures are functionally organized. Today it is more common to study ecosystems as collections of functionally organized units whose interactions do not necessarily result in functional organization at the ecosystem level (e.g., Bodkin 1990). The ability to determine the presence or absence of functional organization at any level of a multi-tier hierarchy is what makes the framework that we propose for the study of cultural diversity so distinctive and useful in the biological sciences (Wilson 2015).

Field sites for the study of cultural evolution. Peregrine is right that we ignored archeology in our target article and that archeologists exemplify the field site approach that we call for. In addition, archeologists are likely to study human cultural ecosystems in relation to biological ecosystems, making them even more exemplary from our perspective. Cultural anthropology and Sociology are also fieldoriented disciplines that are applied to industrial in addition to traditional societies. Nevertheless, most of the commentators resonated to our call for more field sites for the study of cultural evolution (e.g., Botero, Harmon, and Atkinson, Johnson,

Zeitlyn, and Tucker). Several empirical methodologies were discussed, such as Phylogenetic Comparative Methods (Botero, Harmon, and Atkinson), standardized and open-access data for comparisons across field sites (Botero, 
Harmon, and Atkinson), and sociolinguistic methods to delineate meaning systems that, along with norms and institutions, constitute the proximate mechanisms of functionally organized groups (Zeitlyn).

What distinguishes the approach that we call for from other approaches that take place in field settings? First and foremost is the conceptual framework, which informs the questions that are asked. If one were to construct a Venn diagram of human-related research conducted from an ecological and evolutionary perspective and human-related research conducted in everyday settings, the overlap would be very small. Second, when a geographical location is chosen as a field site for an extended period of time, then successive studies can build off each other. This is what distinguishes long term-field sites from single field studies in biological research.

It is easy to regard the creation of a field site as such a large project that it can only be undertaken with a large team and with the help of major funding (Johnson, Tucker). We tried to forestall this impression in our target article and will try again here. The cultural ecosystem approach is first and foremost a conceptual framework that can be employed by individual researchers in addition to teams. A field site can begin as a single study and grow incrementally. This is how the Binghamton Neighborhood project developed (Wilson 2011a). The first project was an unfunded collaboration with the Binghamton City School District that enabled us to study the dynamics of prosociality at a citywide scale (Wilson, O'Brien \& Sesna 2009). That led to several additional studies to validate and extend the results of the first study (e.g., O'Brien and Wilson 2011; O'Brien, Gallup, \& Wilson 2012). Applied research oriented toward improving the quality of life went hand in hand with basic scientific research (e.g. Wilson, Kauffman and Purdy 2011, Wilson 2011b).

The communities surrounding colleges and universities are especially amenable to this incremental approach because of the abundant supply of faculty and students that can become involved in the research. In addition, Johnson makes the fascinating suggestion that colleges and universities can themselves be studied from a cultural ecosystem perspective as a collection of lower-level units that are functionally organized but interact in ways that do not result in functional organization at the university level. This might provide a novel perspective on why it is difficult to be interdisciplinary and how a campus-wide program such as EvoS can help a university function as a single intellectual community (Wilson, Geher, Waldo \& Chang 2011). While EvoS at Binghamton is far from achieving this goal, its mission is indeed to create a "United Ivory Archipelago" (Wilson 2007) and it is a good example of a program that started small and is growing incrementally.

We are amused by Palmer's misreading of our target article to say that major funding is already available for the creation of field sites and that readers should climb aboard the gravy train. Paul has the more accurate assessment: "I wouldn't hold my breath". It is possible to take matters into our own hands, however. The Evolution Institute has created a new Society for the Study of Cultural Evolution (SSCE) that has attracted over 1000 founding members from over 50 nations. The 
creation of field sites is likely to be one of the "grand challenges" that forms the agenda of the SSCE (for more, please visit https://evolutioninstitute.org/project/society-for-the-study-of-cultural-evolution/).

Forming testable hypotheses. For some commentators, our target article gave the impression that the cultural ecosystem approach is hard to use (Tucker) and doesn't lead to the formation of crisp testable hypotheses (Triandis), compared to the axis approach. We are delighted that Triandis provided a commentary, because he is so well known for the axis approach. We were careful to acknowledge the utility of the axis approach in our target article and to describe the cultural ecosystem approach as complementary. We are glad that Triandis's commentary is written in the same spirit. We did present some testable hypotheses in section 4 of our target article but perhaps we didn't make them explicit enough. They include the following:

1) Cultures should be context-specific in their tightness and looseness, depending upon the need for regulation of behavior in any given context.

2) Strong norms (one component of tightness) should vary in their degree of enforcement (the other component of tightness) based on the incentives to violate norms.

3) Strong norms enforced by punishment should be characteristic of extractive societies (sensu Acemoglu and Robinson 2012), in addition to agricultural societies and societies in which everyone is existentially insecure, providing a new environmental context for the study of tightness.

4) The degree to which tightness and looseness can be optimized for each context within a given culture, as opposed to tight and loose syndromes analogous to behavioral syndromes in animal behavior research, is an important research topic, although it is impossible to predict the outcome beforehand.

5) The tight-loose continuum should recreate itself within every new religious tradition. In other words, no matter where a new tradition (such as Methodism or Mormonism) starts out on the tight-loose continuum, congregations will start differing along the continuum as the tradition grows in popularity.

Multilevel selection theory provides additional crisp testable hypotheses, especially concerning the core design principles required for groups to function as corporate units (Wilson, Ostrom and Cox 2013). In general, we think that the cultural ecosystem approach will compare favorably to the axis approach in its ability to formulate testable hypotheses.

More on Tightness and Looseness. We are also delighted that Jackson and Gelfand provided a commentary, given that the research of Gelfand and her associates on the tight-loose axis of cultural variation features so prominently in our target article. One reason that this axis complements the cultural ecosystem approach so well is because both rely centrally on the concept of norms, or 
expectations of appropriate behaviors that often enforced by punishment. Norms define the tight-loose axis and they also play a major (although not exclusive) role in structuring behavioral variation within and among cultures. Jackson and Gelfand endorse a behavioral syndrome view, whereby tightness and looseness have the same "signatures" around the world, no matter what environmental determinants (e.g., societal complexity vs. ecological threat), and the selection of tightness (or looseness) in one context "spills over" to other contexts. Thus, they conjecture that Singapore evolved tight norms to manage intense population density and that the prohibition against flying kites on public beaches is a spillover, or non-adaptive byproduct. More generally, the presumption is that Singapore's tightness cannot be relaxed at will, much as its leaders may wish to do so for special purposes, for instance to promote innovation in targeted areas of the economy. The more the behavioral syndrome perspective turns out to be the case, the more appropriate it is to think about tightness and looseness as a single axis of cultural variation. Jackson and Gelfand stress, as we do, that these questions can only be answered by more empirical research.

We would like to offer a counterexample to Jackson and Gelfand's example of Singapore, in which extreme tightness and extreme looseness can be combined in a single culture. Two of us (Wilson and MacDonald) are beginning to study a movement called Interspirituality (Johnson and Ord 2013) and also the burgeoning number of intentional communities that are forming in America and around the world (Lockyer and Voltero 2015). One Ecovillage called Dancing Rabbit (http://www.dancingrabbit.org) shows how extreme tightness and extreme looseness can be combined in a single functionally organized group. Dancing Rabbit is extremely tight in its ecological norms. Members must sign a covenant abiding by the village rules and serious infractions would result in exclusion. For members that uphold the ecological norms, however, any spiritual belief (including atheism), sexual orientation, or other life style (as long as it doesn't harm others) is tolerated and intolerance would itself be punished. The combination of extreme tightness and extreme looseness appears to make for a vibrant community that "walks the walk" with respect to environmentally sustainable practices and provides a high quality of life for members of the group. We realize that this example is conjectural, along with Jackson and Gelfand's example of Singapore, and that more research is required to understand the constraints on varying tightness and looseness within any given culture.

Cultural Diversity vs. Religious Diversity. What does the cultural ecosystem approach have to say about religious diversity per se, as opposed to cultural diversity? We subscribe to Bloch's (2008) statement quoted by Tucker that religion is "nothing special"; i.e. a subset of something more general, which Tucker aptly describes as "cultural cognition" and "part of the human ability to imagine "other worlds', which forms the basis of most social institutions, including kinship". We sometimes use the more compact term "meaning system" in the same way. A strength of the cultural ecosystem approach is that it studies religious groups and non-religious groups as part of the same cultural ecosystem, no matter what specific 
definition of religion is used. This makes it possible to ask a host of questions concerning the advantages of religious groups compared to secular groups in their immediate vicinity, the movement of individuals in and out of religious groups (as discussed in the target article), and so on. A good example concerns the growth of strict churches and decline of lax churches in America chronicled by Kelly (1972; while the strict-lax axis is not exactly the same as the tight-loose axis, the same statement could be made about tight and loose churches). We think that the appeal of a lax church depends upon the social acceptability of not belonging to any church. In a culture where it is necessary to belong to a church to be socially respected, such as America during the $19^{\text {th }}$ and early $20^{\text {th }}$ centuries, then lax churches were very popular. It was the availability of a third option (no church) that made lax churches weak. This is another specific hypothesis that emerges from the cultural ecosystem approach. We agree with Johnson that syncretic religions and new age spiritual movements are fascinating to study, as we are starting to do with our study of the Interspiritual and Intentional Communities movements described in the previous section.

We hope that our target article and the commentaries promote the study of cultural diversity as like biological diversity. We look forward to what future research employing the cultural ecosystem approach will bring. 


\section{Literature Cited}

Acemoglu, D., \& Robinson, J. (2012). Why Nations Fail: The Origins of Power,Prosperity, and Poverty. 2012. New York: Crown.

Bloch, M. (2008). Why religion is nothing special but is central. Philosophical Transaction of the Royal Society B, 363, 2055-2061.

Bodkin, B. B. (1990). Discordant Harmonies: a new ecology for the twenty-first century. New York: USA, Oxford University Press USA.

Henrich, J., Boyd, R., \& Richerson, P. J. (2008). Five Misunderstandings about Cultural Evolution. Human Nature, 19, 119-137.

Johnson, K., \& Ord, D. (2013). The Coming Interspiritual Age. Vancouver: Namaste.

Kelly, D. M. (1972). Why conservative churches are growing: a study in the sociology of religion. Macon, GA: Mercer University Press.

Lockyer, J., \& Veteto, J. R. (2015). Environmental Anthropology Engaging Ecotopia: Bioregionalism, Permaculture, and Ecovillages. Oxford, NY: Berghahn Books.

Margalef, R. (1963). On Certain Unifying Principles in Ecology. American Naturalist, 97, 357-374.

O’Brien, D. T., Gallup, A. C., \& Wilson, D. S. (2012). Residential mobility and prosocial development within a single city. American Journal of Community Psychology, 50(1-2), 26-36. http://doi.org/10.1007/s10464-011-9468-4

O’Brien, D. T., \& Wilson, D. S. (2011). Community perception: the ability to assess the safety of unfamiliar neighborhoods and respond adaptively. Journal of Personality and Social Psychology, 100(4), 606-20. http://doi.org/10.1037/a0022803

Paul, R. A. (2015). Mixed Messages: Cultural and Genetic Inheritance in the Constitution of Human Society. Chicago: University of Chicago Press.

Richerson, P. J., \& Boyd, R. (2006). Not by genes alone: how culture transformed human evolution. Chicago: University of Chicago Press.

Wilson, D. S. (2007). Evolution for Everyone: How Darwin's Theory Can Change the Way We Think About Our Lives. New York: Delacorte.

Wilson, D. S. (2011a). The Neighborhood Project: Using Evolution to Improve My City, One Block at a Time. New York: Little, Brown.

Wilson, D. S. (2011b). The Design Your Own Park Competition: Empowering Neighborhoods and Restoring Outdoor Play on a Citywide Scale. American Journal of Play, 3, 538-551.

Wilson, D. S. (2013). Human Cultures are Primarily Adaptive at the Group Level (with comment). Cliodynamics: The Journal of Theoretical and Mathematical History, 4(1).

Wilson, D. S. (2015). Does Altruism Exist? Culture, Genes, and the Welfare of Others. New Haven: Yale University Press.

Wilson, D. S., Geher, G., Waldo, J., \& Chang, R. (2011). The EvoS Consortium: Catalyzing Evolutionary Training in Higher Education (Introductory article to a special issue of Evolution: Education and Outreach) devoted to EvoS . Evolution: Education and Outreach, 4(1), 8-10. 
Wilson, D. S., Kauffman, R. A., \& Purdy, M. S. (2011). A Program for At-risk High School Students Informed by Evolutionary Science. PLOS ONE, 6(11), e27826.

http://doi.org/10.1371/journal.pone.0027826

Wilson, D. S., O’Brien, D. T., \& Sesma, A. (2009). Human prosociality from an evolutionary perspective: variation and correlations at a city-wide scale. Evolution and Human Behavior, 30(3), 190-200. http://doi.org/10.1016/j.evolhumbehav.2008.12.002

Wilson, D. S., Ostrom, E., \& Cox, M. E. (2013). Generalizing the core design principles for the efficacy of groups. Journal of Economic Behavior \& Organization, 90, S21-S32. http://doi.org/10.1016/j.jebo.2012.12.010 